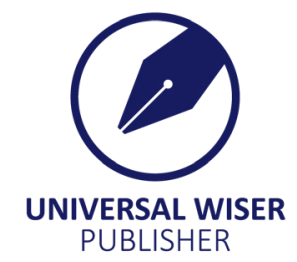

\title{
General Perspectives on Water and Fluid Borne Microorganisms in Bangladesh
}

\author{
Asma Akter Bhuiyan ${ }^{1}$, Rashed Noor ${ }^{2 *}$ \\ ${ }^{1}$ School of Life Sciences (SLS), Independent University, Bangladesh (IUB), Plot 16, Block B, Aftabuddin Ahmed Road, Bashundhara, \\ Dhaka 1229, Bangladesh \\ ${ }^{2}$ Department of Microbiology, School of Life Sciences (SLS), Independent University, Bangladesh (IUB), Plot 16, Block B,Bashundhara, \\ Dhaka 1229, Bangladesh \\ E-mail: rashednoor@iub.edu.bd
}

\begin{abstract}
Clinical complications especially diarrhoea and other enteric diseases have long been taking place in the comparatively densely populated regions with the general lack of knowledge on hygiene as well as lack of facilities / amenities. Water and the street vended juices, including the carbonated beverages, are frequently triggering sickness especially among the children. The potential bacteria, viruses and parasites residing within the different sources of waters and in a wide range of liquid products have long been investigated worldwide for the maintenance of public health sustainability. On the basis of previous literature and reports, the present review focused on the pathogenic microorganisms with particular emphasis on microbial status of water and the commonly available drinks consumed by the mass people in Bangladesh. The possible events applicable to ensure the microbiological quality is also discussed.
\end{abstract}

Keywords: water, juices, carbonated beverages, microorganisms, diseases, public health

\section{Introduction}

Potable water as well as various drinks and fluids are the foremost elemental prerequisites for surviving a sound life and so it is a major concern globally to control the manifestations. However, waterborne disease is a global burden which is estimated to cause more than 2.2 million premature deaths per year and higher cases of illness every day, including diarrhoea, gastrointestinal diseases and systematic illnesses etc ${ }^{[1-3]}$. There are different types of spoilage and pathogenic microorganisms such as bacteria, viruses, fungal species, toxins, trace elements which are responsible for triggering several waterborne and the foodborne disease outbreaks world-wide ${ }^{[4-9]}$. Developing countries like Bangladesh is more venturesome due to the lack of knowledge of handling, storing food or water raw samples 'from production to consumer'; besides, poor hygiene of maintaining food and water, human induced adulterated food, fabrication etc. are also playing roles to spread several diseases or even outbreaks to epidemics ${ }^{[10-13]}$. So, to keep control the human's basic rights on food safety the 'Food Safety Act 2013' has also been enacted in Bangladesh through repealing and re-enacting the existing outdated laws in these regards ${ }^{[14-16]}$.

In recent years, different types of beverages including carbonated soft drinks, fruit juices, energy drinks and nonalcoholic malt beverages etc. have been drawing the attention of lots of consumers especially of the children not only in Bangladesh but also in other countries too, due to the pleasant flavour and taste, attractive presentations. Actually, these kinds of beverages contain carbon dioxide $\left(\mathrm{CO}_{2}\right)$, natural or artificial sweetening agent, acid (citric acid, malic acid, and phosphoric acid), natural or artificial flavours, preservatives, colours which are very often questionable regarding their food grade quality an in course of their manufacturing and packaging maintaining the appropriate good manufacturing practice (GMP) and chemical or microbiological quality ${ }^{[17,18]}$. This is to be pondered that soft drink consumption is a controversial public health issue as evident by their impact on obesity and many other related health problems, especially among the children ${ }^{[19,20]}$. Indeed, a major question lies upon the sugar-sweetened soft drink consumption whether they impart any benefit to the mass public health; and unfortunately there is no such nutritional or health benefit out of consumption of those soft drinks ${ }^{[19]}$. Rather, type-2 diabetes and the onset of cardiovascular diseases upon consumption of soft drinks are also very likely ${ }^{[21]}$. Therefore, implementing strict legislative actions with certain food dispensing laws are essential for the sustainable maintenance of mass public health which is unfortunately absent in Bangladesh ${ }^{[22]}$. The current review

Copyright (C2020 Rashed Noor, et al.

DOI: https://doi.org/10.37256/amtt.122020480

This is an open-access article distributed under a CC BY license

(Creative Commons Attribution 4.0 International License)

https://creativecommons.org/licenses/by/4.0/ 
thus focused on the potential pathogenic microorganisms with special emphasis on viral pathogens isolated from different waters and the soft- and carbonated beverages. The possible measures along with the microbiological quality assurance of different products have been discussed as well.

\section{Microbial contamination aspects of the sweetened soft drinks}

Microbial contamination has been considered a major reason for different sporadic diseases in humans (like the onset of gastrointestinal diseases mostly including abdominal cramps, diarrhoea, etc.); and markedly unsafe water is one of the leading issues ubiquitously to generate contamination ${ }^{[10-13,23,24]}$. Contamination of water mostly happens due to the lack of appropriate purification system of water supply ${ }^{[14,16]}$. As a result, the contaminated and microbiologically unsafe waters are eventually used for industrial manufacturing of a variety of beverages; and thus, microbes or the microbial components like the endotoxins, Shigatoxins, pyrogens, etc. propagate into the bulk of the product manufactured which in turn account for the transmission of enteric diseases into the consumers upon consumption of the commercial beverages like various juices drinks ${ }^{[6-9,25-27]}$. Moreover, fruit juices and different types of raw juices are sold by street food traders who indeed lack the knowledge on personal hygiene, concept on the importance of maintain or preserving the products in an appropriate way, irrational use of preservatives like high concentrations of formalin in fruits ${ }^{[6]}$.

\section{Water borne pathogens and associated diseases}

\subsection{Bacterial infections}

Waterborne diseases are shedding into a community especially within the slum area not only due to the direct ingestion of contaminated water but also due to the high level of faecal-oral transmission in the densely populated area where fecal materials can readily pollute the surface water which in turn may leach along the ground waters. Such a consequence renders the water reservoirs to serve as suitable habitats for different bacteria, viruses, unicellular intestinal parasites, and intestinal worms etc., triggering an array of diseases principally including typhoid, dysentery, diarrhoea, cholera, constipation, jaundice, allergy, infections on lungs, urinary tract infection (UTI), chronic gastritis, ulcerative diseases, gastric cancer and dermatitis ${ }^{[28]}$. Using such contaminated water as raw material for the preparation of locally vended products is not unlikely in certain countries which is really a great health related issue.

Indeed, death due to a range of water-borne diseases is significant in Bangladesh; and unfortunately the untreated industrial effluents, improperly disposal of domestic wastes and the agricultural runoffs may augment varieties of water borne diseases ${ }^{[2,3,29]}$. The major water borne bacterial pathogens have been identified as Aeromonas spp., Enterbacter spp., Enterococcus spp., Escherichia coli and fecal coliforms, Klebsiella spp., Campylobacter spp., Clostridium spp., Listeria spp., Burkholderia pseudomallei, Helicobacter pylori, Pseudomonas spp., Salmonella spp., Shigella spp., Staphylococcus spp., and Vibrio cholerae ${ }^{[2,29]}$. As mentioned earlier, the use of heavily contaminated water or the inappropriate purification of the water during the manufacturing of the beverages can thus lead to the heavy accumulation of several bacteria within the finished product. The onset of gastrointestinal diseases such as shigellosis, campylobacteriosis, E. coli O157:H7 haemorrhagic colitis, yersiniosis, cholera, etc. is not unlikely upon consumption of such soft drinks and fruit juices etc. Such enteric diseases account for nearly quarter of illnesses in Bangladesh.

\subsection{Viral infections}

Viral pathogens need low infectivity dose of 100 or less cells and may shed with extremely high numbers which can lead to the large outbreaks in a relatively short time. Hence, many viral infections arise and cause many acute to severe infections in a colonized individual which may last for few days but remains asymptomatic. The most prevalent water borne viruses are known to be Rotavirus, Calicivirus, Sapovirus, Astrovirus, Adenovirus Norwalk virus, Hepatitis A, E viruses, Polyomaviruses, Cytomegalovirus viruses, and Influenza viruses ${ }^{[1,30]}$.

Indeed, fecal contamination of drinking water has been found to be associated with the Hepatitis E virus (HEV) outbreaks in endemic areas ${ }^{[31]}$. Diarrhoea is considered one of the most common leading water borne diseases; and interestingly, the Norovirus infections in diarrhea patients attending an urban and a rural hospital were noticed by Lee and colleagues in $2019^{[32]}$. The prevalence and the subsequent dreadful effect of Group A rotavirus, triggering a substantial proportion of diarrhoea related deaths, is known worldwide among the children under five years ${ }^{[33]}$. As viral pathogen primarily requires typical living host or cell preference (called tropism) to conduct their metabolic activities and multiply, hence the water borne infections can privilege the cell lining of host's intestinal tract and be dispersed by shedding into the stool or through emesis ${ }^{[34]}$ (Figure 1). Besides, water borne viral pathogen can transmit viruses through inhalation (e.g., showering) or contact with skin and eyes (e.g., swimming) causing respiratory and ocular infections ${ }^{[30]}$. Common viral 
diseases due to consumption of microbiallly contaminated water or drinks include gastroenteritis, meningitis, respiratory disease, conjunctivitis, myocarditis, paralysis and hepatitis ${ }^{[35]}$. Basically, for waterborne viral infections difficulties arises regarding the detection of the exact pathogen due to technical limitations in the resource poor settings, data scarcity on the epidemiology of the common and frequent diseases ${ }^{[27]}$. For example, some viruses like Picornaviruses, Toro viruses, Enteroviruses, Reoviruses, and Parvoviruses were identified in faecal specimens from children and adults with gastroenteritis and HIV-infected patients as well. Additionally, the $\beta$-coronaviruses have been associated to humans gastroenteritis, neonatal necrotising enterocolitis ${ }^{[36]}$.

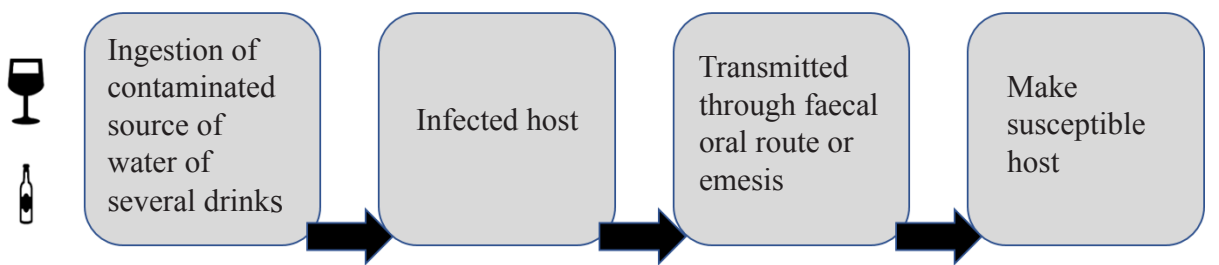

\begin{abstract}
The framework has drawn to simply explain how contaminated water sources can make other host susceptible towards asymptomatic with viral diseases because they are mostly shedding by faecal and spew of infected host which is going to miscellaneous with different water source and transmitted through faecal oral route or contact with skin and eyes of infected host and make susceptible host
\end{abstract}

Figure 1. Simplified framework to understand the basic shedding of viral diseases by ingesting industrially produced several drinks

\title{
3.3 Parasitic and fungal infections
}

Besides bacterial and viral infections, some parasites are best candidates for endemic transmission because they found ubiquitously in water intended for drinking and responsible for severe manifestations such as Cryptosporiosis, Amebiasis etc. are caused by protozoan Cryptosporidium parvum, Entamoeba histolytica, Toxoplasma gondii etc. Importantly, they are highly resistant to chemical disinfecting procedure and relevant environmental factors which is biggest concern to enhance risk factors for immunocompromised individuals ${ }^{[36]}$. Besides, prevalence of yeast and mould cells were also reported from the beverage products with the emphasis of the importance of effective sanitizing practice in retail settings ${ }^{[37]}$.

\section{Prevention and protection against pathogens}

For the implementation of the preventive measures against water and beverage borne pathogens, the involvement of defined legislative bodies in food sector is essential. Routine microbiological quality control, maintain GMP and the total quality management (TQM) during the production process; assessment of the possible risk factors is required for the commercialization of the products for the sake of maintain sound public health. Adequate knowledge and training on food safety and security, appropriate equipment, tools and test-kits for inspection and sample collections, rapid identification test facilities, the molecular set up for the precise analysis of microorganisms and microbial products within the finished product and in the raw materials are essential as well. Therefore, regulatory bodies and the Governmental health sectors should take necessary steps to furnish the required logistics and disseminate appropriate information towards the mass people about sanitary conditions ${ }^{[10-11,13-16]}$.

In perspective of Bangladesh, this is to be mentioned that the Bangladesh Water Safety Act 2013 was formed by the Ministry of Water Resources (MoWR) along with the comprehensive water safety plans (WSPs) with the aim of establishment of efficient, effective, scientifically based regulations of water safety including the implementations and functioning of different water sources, supplying, risk assessments, etc ${ }^{[38,39]}$. A simplified model of such safety regulatory framework has been proposed in Figure 2, projecting the schematic flow showing typical manufacturing strategy of beverages keeping the principles of GMP, TQM, and the hazard analysis: critical control point (HACCP) ${ }^{[13,15-16]}$. Such regulatory measures are legalised by the local Food and Drug Administration (FDA) which gives standardization for regulating the manufacturing industry worldwide. According to FDA, GMP deals with proper design, monitoring, and control of manufacturing processes and facilities and cGMP reminds manufacturers that they must apply up to date technologies and systems to comply the regulation ${ }^{[16]}$. Additionally, HACCP addresses the standardization of food and water safety by analysing several hazards from raw material production, procurement and handling, to manufacturing, distribution and consumption of the finished product ${ }^{[15,16]}$. 


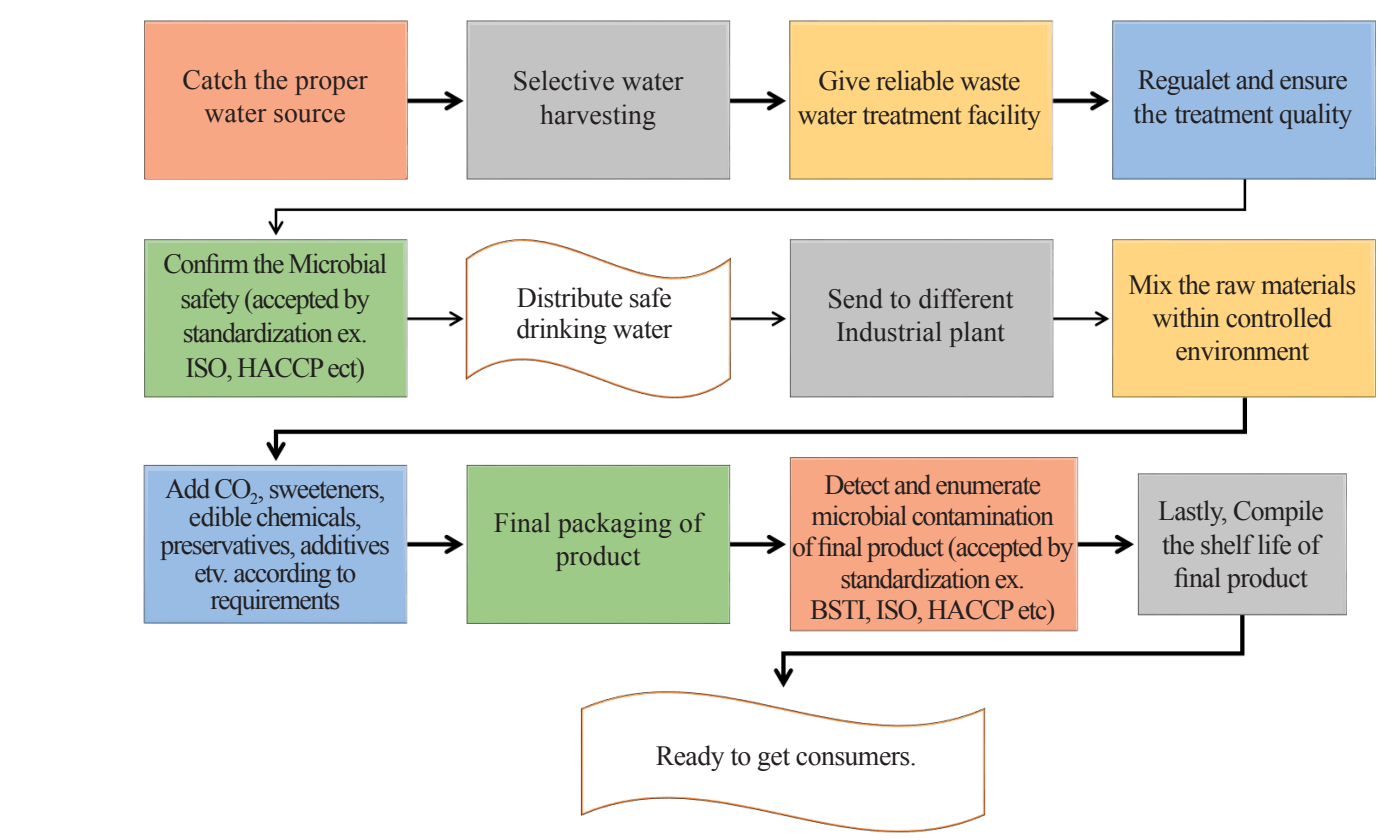

The proposed schematic framework has emphasized the basic significant of proper planning to get 'safe drinking water' industrially and distribute of these waters for vast production. Because as various recreational drinks have passively mixed with water which may affect by microbial contamination if proper regularity bodies haven't maintained industrially by producers.

The possible way to keep national and international standardization (BSTI, ISO, HACCP) with strict imposed of legislation from initial to final packaging of production which would reserve the consumer right to live healthy live). ISO: International Organization for Standardization; HACCP: Hazard Analysis and Critical Control Points; BSTI: Bangladesh Standards \& Testing Institution.

Figure 2. A simplified schematic framework to get Safe Drinking water and Various refreshment drinks Industrially

However, developing countries like Bangladesh where the problem arises mostly when different raw fruit juices, drinks etc. are sold by different street vendors and standardization has become an incubus there ${ }^{[6]}$. That's why stringent hygienic control must be implemented with aid of legislation for random vendors and importantly for handlers as stated earlier. Because, introduction of different pathogens (Bacteria, virus, parasite, mycotoxins) in water or food chain is a likely event where infected handlers are in contact with people (e.g. young children) at special risk of being contaminated and becoming a source of pathogens specifically viruses during manufacture operations, as mostly the viral transmissions may take place asymptomatically ${ }^{[40]}$. Besides, for developing water safety plans (WSP) several risk assessments models have been improvised specifically the Quantitative microbial risk assessment (QMRA) which is an approach to monitor pathogen in water source and progression to estimate the health impacts of human exposure to pathogens ${ }^{[41]}$. Following, some indicators or novel markers such as Campylobacter, enterovirus, Cryptosporidium, and Giardia are used to predict the presence of all pathogens which would improve risk assessment and management actions ${ }^{[1]}$. So, the adaptation of QMRA would help to estimate the level of risk from different pathogens, to understand dynamics of microbial populations in drinking water systems and to identify the strategies for reducing health risks and waterborne outbreaks ${ }^{[1]}$.

Finally, consumers also need general cautiousness about health on hygiene, shelf life of a product etc. moreover microbial spoilage before having various of drinks to reduce waterborne diseases and microbial toxicities. And, standardized surveillance networks are essential for documentation of microbial disease outbreaks of waterborne infections which would aid to take preventive measures earlier to stop further ${ }^{[34]}$. Importantly, the fact towards prevention and prediction etc. is an economic cost and so one failure at any point makes barriers for next steps to provide protection.

\section{Conclusion}

Last but not the least, waterborne disease can appear by drinking water or recreational water but in developing countries, it isn't considered as a major public health problem so that prevention of water-related virus contamination remains a perennial challenge both in developing and developed societies owing to its global trade. Developing countries like Bangladesh where current water treatment facilities do not ensure and producers aren't concerned about complete removal of water contaminants during industrial production which represents a public health threat. The most dangerous point is to ponder that different street vendors are using the intrinsically contaminated water when making of several refreshment juices and people are unknowingly ingested and infected by it. Therefore, typical food borne disease onset 
occurs which is of mass public health threat.

\section{Reference}

[1] Castillo FYR, Muro AL, Jacques M, Garneau P, González FJA, Josée Harel, Barrera ALG. Waterborne pathogens: Detection methods and challenges. Pathogens. 2015; 4: 307-334.

[2] Acharjee M, Rahman F, Jahan F, Noor R. Bacterial proliferation in Municipal water supplied in Mirpur Locality of Dhaka City, Bangladesh. CLEAN-Soil, Air, Water. 2014; 42(4): 434-441.

[3] Munshi SK, Rahman MM, Noor R. Detection of virulence potential of diarrheagenic Escherichia coli isolated from surface water of rivers surrounding Dhaka City. Journal of Bangladesh Academy of Sciences. 2012; 36(1): 109-121.

[4] Ahmed T, Acharjee M, Rahman MS, Meghla M, Jamal J, Munshi SK, Noor R. Microbiological study of drinking water: Qualitative and quantitative approach. Asian Journal of Microbiology, Biotechnology and Environmental Science. 2013; 15(4): 23-30.

[5] Ahmed T, Baidya S, Sharma BC, Malek M, Das KK, Acharjee M, Munshi SK, Noor R. Identification of drug-resistant bacteria among export quality shrimp samples in Bangladesh. Asian Journal of Microbiology, Biotechnology and Environmental Science. 2013; 15(4): 31-36.

[6] Sarker N, Islam S, Hasan M, Kabir F, Uddin MA, Noor R. Use of multiplex PCR assay for detection of diarrheagenic Escherichia coli in street vended food items. American Journal of Life Sciences. 2013; 1(6): 267-272.

[7] Marjan S, Das KK, Munshi SK, Noor R. Drug-resistant bacterial pathogens in milk and some milk products. Nutrition \& Food Science. 2014; 44(3): 241-248.

[8] Noor R, Uddin MA, Haq MA, Munshi SK, Acharjee M, Rahman MM. Microbiological study of vendor and packed fruit juices locally available in Dhaka city, Bangladesh. International Food Research Journal. 2013; 20(2): 10111015.

[9] Rahman T, Hasan S, Noor R. An assessment of microbiological quality of some commercially packed and fresh fruit juice available in Dhaka city: A comparative study. Stamford Journal of Microbiology. 2011; 1(1): 13-18.

[10] Noor R, Malek M, Rahman MS, Meghla M, Acharjee M, Rahman MM. Assessment of survival of pathogenic bacteria in raw fresh vegetables through in vitro challenge test. International Journal of Food Contamination. 2015; 2: 15.

[11] Noor R, Munna MS. Emerging diseases in Bangladesh: Current microbiological research. Tzu Chi Medical Journal. 2015; 27(2): 49-53.

[12] Noor R, Hasan MF, Munna MS, Rahman MM. Demonstration of virulent genes within Listeria and Klebsiella isolates contaminating the export quality frozen shrimps. International Aquatic Research. 2015; 7(2): 157-161.

[13] Noor R, Feroz F. Requirements for microbiological quality management of the agricultural products: An introductory review in Bangladesh perspectives. Nutrition \& Food Science. 2015; 45(5): 808-816.

[14] Noor R. Novel approaches in food microbiology: Assuring food safety and public health. Res Rev Biosci. 2019; 14(1): 148.

[15] Noor R, Maniha SM. Opportunistic food borne infections: A brief review. Acta Scientific Microbiology. 2019; 2(7): 67-71.

[16] Noor, R., Feroz, F. Food safety in Bangladesh: A microbiological perspective. Stamford Journal of Microbiology. 2017; 6(1): 1-6.

[17] Singh GM, Micha R, Khatibzadeh S, Shi P, Lim S, Andrews KG, et al. Global, regional, and national consumption of sugar-sweetened beverages, fruit juices, and milk: A systematic assessment of beverage intake in 187 countries. PLoS One. 2015; 10(8): e0124845. Available from: doi: 10.1371/journal.pone.0124845.

[18] Juvonen R. Virkajärv V. Priha O., Laitila A. Microbiological spoilage and safety risks in non-beer beverages. Vtt Tiedotteita-Research Notes 2599. 2011.

[19] Vartanian LR, Schwartz MB, Brownell KD. Effects of soft drink consumption on nutrition and health: A systematic review and meta-analysis. Am J Public Health. 2007; 97(4): 667-675.

[20] Gillis LJ, Bar-Or O. Food away from home, sugar-sweetened drink consumption and juvenile obesity. J Am Coll Nutr. 2003; 22: 539-545.

[21] Crichton GE, Elias MF, Torres RV. Sugar-sweetened soft drinks are associated with poorer cognitive function in individuals with type 2 diabetes: The Maine-Syracuse longitudinal study. Br J Nutr. 2016; 115(8): 1397-405.

[22] Azeredo CM, Leite MA, Rauber F, Ricardo CZ, Levy RB. Are laws restricting soft drinks sales in Brazilian schools able to lower their availability? Rev Saude Publica. 2020; 54: 42.

[23] Yasmin S, Parveen S, Munna MS, Noor R. Detection of Salmonella spp. and microbiological analysis of milk and milk based products available within Dhaka Metropolis, Bangladesh. British Microbiology Research Journal. 2015; 5(6): 474-480.

[24] Noor R, Hasan MF, Rahman MM. Molecular characterization of the virulent microorganisms along with their drug-re- 
sistance traits associated with the export quality frozen shrimps in Bangladesh. SpringerPlus. 2014; 3: 469.

[25] Kregiel D. Health safety of soft drinks: contents, containers, and microorganisms. Biomed Res Int. 2015; 2015: 128697.

[26] Kregiel D, James SA, Rygala A, Berlowska J, Antolak H, Pawlikowska E. Consortia formed by yeasts and acetic acid bacteria Asaia spp. in soft drinks. Antonie Van Leeuwenhoek. 2018; 111(3): 373-383.

[27] Bosch A, Guix S, Sano D, Pintó RM. New tools for the study and direct surveillance of viral pathogens in water. Curr Opin Biotechnol. 2008; 19(3): 295-301.

[28] Sultana R, Tamason CC, Carstensen LS, Ferdous J, Hossain ZZ, Begum A, Jensen PKM. Water usage, hygiene and diarrhea in low-income urban communities-A mixed method prospective longitudinal study. MethodsX. 2019; 6: 2822-2837.

[29] Hasan MK, Shahriar A, Jim KU. Water pollution in Bangladesh and its impact on public health. Heliyon. 2019; 5: 1-23.

[30] Gall AM, Mariñas BJ, Lu Y, Shisler JL. Waterborne viruses: A barrier to safe drinking water. Pathogen. 2015; 11(6): 1-7.

[31] Haque F, Banu SS, Ara K, Chowdhury IA, Chowdhury SA, Kamili S, Rahman M, Luby SP. An outbreak of hepatitis E in an urban area of Bangladesh. J Viral Hepat. 2015; 22(11): 948-956.

[32] Hyunah Lee, Donguk Kim, Seongmin Park, Jongjin Park, Hae-Sung Nam, Jinha Choi, Junhyuk Park. An norovirus outbreak at a local festival in Chungnam Korea. Journal of Bacteriology and Virology. 2019; 2(81). Available from: doi: $10.4167 /$ jbv.2019.49.2.81.

[33] Haque W, Haque J, Barai D, Rahman S, Moni S, Hossain ME, Faruque ASG, Ahmed S, Zaman K, Rahman M. Distribution of rotavirus genotypes in Dhaka, Bangladesh, 2012-2016: Re-emergence of G3P[8] after over a decade of interval. Vaccine. 2018; 36(43): 6393-6400.

[34] Koopmans M. Bonsdori CHV, Vinje J. Medici D., Monroe S. Foodborne viruses. FEMS Microbiology Reviews. 2002; 26: 187-205.

[35] IFST (Institute of Food Science \& Technology). Information Statement on Foodborne Viral Infections. 2018.

[36] Leclerc H, Schwartzbrod L, Dei-Cas E. Microbial agents associated with waterborne diseases. Critical Reviews in Microbiology. 2002; 28(4): 371-409.

[37] Park YJ, Chen J. Microbial quality of soft drinks served by the dispensing machines in fast food restaurants and convenience stores in Griffin, Georgia, and surrounding areas. J Food Prot. 2009; 72(12): 2607-2610.

[38] Water governance in Bangladesh. Challenges and opportunities around policy, institutional function and implementation for a sustainable water future. 2015.

[39] Rahman MM, Paul CK. Implementation of water safety plans in Bangladesh: Situation and need analysis. J. Sci. Foundation. 2011; 9(1\&2): 141-161.

[40] Koopmans M., Duizer E. Foodborne viruses: An emerging problem. International Journal of Food Microbiology. 2003; 90: 23-41.

[41] Petterson SR, Ashbolt NJ. QMRA and water safety management: Review of application in drinking water systems. Journal of Water and Health. 2016; 14(4): 571-589. 